\title{
ECHOCARDIOGRAPHIC FINDINGS IN CHRONIC OBSTRUCTIVE PULMONARY DISEASE PATIENTS
}

\author{
Khatri $D^{1}$, Karki $P^{1}$, Shrestha $D B^{2^{*}}$, Khatri $R^{1}$, Thapa $R K^{1}$, Panta $C^{1}$, Budhathoki $L^{3}$
}

\section{Affiliation}

1. Consultant, Department of Internal Medicine, Nepalese Army Institute of Health Sciences(NAIHS), Shree Birendra Hospital, Chhauni

2. Medical Officer, Shree Birendra Hospital, Chhauni

3. Lecturer, Department of Community Medicine, Nepalese Army Institute of Health Sciences(NAIHS)

\section{ARTICLE INFO}

\section{Article History}

Received : 26 January, 2018

Accepted : 8 March, 2018

Published : 30 April, 2018

(C) Authors retain copyright and grant the journal right of first publication with the work simultaneously licensed under Creative Commons Attribution License CC - BY 4.0 that allows others to share the work with an acknowledgment of the work's authorship and initial publication in this journal.

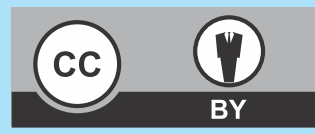

ORA 52

DOI: $\underline{\text { http://dx.doi.org/10.3126/bjhs.v3i1.19738 }}$

\author{
* Corresponding Author \\ Dr. Dhan Bahadur Shrestha \\ Medical Officer \\ Nepalese Army Institute of Health Sciences (NAIHS) \\ Shree Birendra Hospital, Chhauni \\ E-mail :medhan75@gmail.com \\ http://orcid.org/000-0002-8121-083X
}

\section{Citation}

Khatri D, Karki P, Shrestha DB, Khatri R, Thapa RK, Panta C, Budhathoki L. Echocardiographic Findings in Chronic Obstructive Pulmonary Disease Patients. BJHS 2018;3(1)5:342 - 345 .

\section{ABSTRACT}

\section{Introduction}

Chronic Obstructive Pulmonary Disease (COPD) is parenchymal lung disease with systemic effects and hemodynamic alteration more so in pulmonary circulation. In COPD, right ventricular (RV) after load increases due to structural and mechanical changes in the pulmonary vascular bed leading to increase in pulmonary arterial pressure which also leads to alteration in structure and function of RV. In COPD, congestive cardiac failure and ventricular dysfunction may coexist and demands proper assessment and management of dual condition.

\section{Objectives}

This study was aimed to study the effect of COPD in cardiac anatomical and functional parameters in COPD patients in Shree Birendra Hospital.

\section{Methodology}

This study was a retrospective review of hospital data on echocardiographic findings in 86 COPD patients visiting the outpatient department (OPD) in six months from June 2016 to December 2016. Available data was entered, edited and analyzed using Statistical package for social sciences (SPSS) version 22

\section{Results}

Among 86 cases studied, $43 \%$ had dilated RA and $41 \%$ with dilated RV, $24 \%$ with dilated LA and dilated LV in $22 \%$. Normal pulmonary artery pressure was present in $41(48 \%)$ cases and 45(52 \%) individuals were having PAH. Among valvular disorder tricuspid regurgitation was commonest (50\%). Left ventricle abnormalities like dilated left ventricles, LVDD, concentric ventricular hypertrophy, LVSD were also presented in significant number of COPD patients counting $22 \%, 37 \%, 7 \%, 30 \%$ respectively. Among the various factors analyzed in echocardiogram; there was significant association between the PAH with right atrial dilatation, right ventricular dilatation, left atrial dilatation, LVDD, tricuspid regurgitation $(p<0.05)$ while rest of the parameters were not statistically significant association.

\section{Conclusion}

COPD in most instances associated with some form of cardiac abnormalities like PAH, LVDD, LVSD, TR, dilated cardiac chambers so echocardiographic evaluation in timely basis has pivotal role in COPD cases to detect hemodynamic and mechanical alterations.

\section{KEYWORDS}

Chronic obstructive pulmonary disease, echocardiography, left ventricular systolic dysfunction, pulmonary arterial hypertension 


\section{INTRODUCTION}

Chronic Obstructive Pulmonary Disease (COPD) is parenchymal lung disease with profound systemic effects like chronic hypoxemia leading to pulmonary arterial hypertension. COPD alters hemodynamics leading to cardiac parametric alteration and if severe even right heart failure. ${ }^{1}$ So, it is a commonly encountered diagnosis in medicine having high disease morbidity and mortality. COPD is associated with structural and mechanical changes in the pulmonary vascular bed that increase Right Ventricular (RV) after load. Impaired RV systolic function, hypertrophy and dilatation present even at slight increase of mean pulmonary arterial pressure, which indicates early impact on RV function and structure in patients with COPD. ${ }^{2}$ Transthoracic echocardiography is a useful tool to detect various cardiac abnormalities demanding special treatment which may need special care. ${ }^{3.5}$ Chronic Heart failure (CHF) and COPD frequently coexist, and ventricular dysfunction has poor outcome. ${ }^{5}$ These days this investigation modality is available in most part of the world and even in Nepal. ${ }^{6}$ Reversible cardiac ischemic defects are common in advanced COPD patients with left ventricular diastolic dysfunction (LVDD) without the presence of common risk factors but has to be detected and well managed to prevent dire consequences.

Present study was done to study the effect of COPD in cardiac anatomical \& functional parameters and observe the left ventricular systolic dysfunction (LVSD) associated with cases of COPD among veterans and their families in a tertiary center at Kathmandu

\section{METHODOLOGY}

This study was retrospective review of, hospital data on echocardiographic findings in 86 COPD patients visiting the OPD in six months from June 2016 to December 2016 in Shree Birendra Army Hospital (SBH), Chhauni. SBH is the only tertiary level hospital for Nepalese serving soldier, veterans and their family. The diagnosis of COPD was made based on the history, signs and symptoms and in selective cases radiological investigations like chest X-ray, spirometry, electrocardiography and echocardiography. Among the patient with some anticipated cardiovascular remodeling due to COPD is usually advised for the echocardiographic assessment in our institution. The properly managed data in record keeping book in six months were addressed for this study after ethical approval from institutional review committee.

Echocardiographic examination was done to see cardiac structural and functional abnormalities due to remodeling associated with underlying COPD. Patients having other respiratory and cardiovascular comorbidities like bronchial asthma, tuberculosis, hypertension, valvular heart diseases were excluded. Those echocardiographic findings were recorded manually in the record book of Echo-room. Available data was retrieved, entered, and analyzed using Statistical package for social sciences (SPSS) version 22. Chi-square test was used to see the association between variables studied.

\section{RESULTS}

Among 86 cases analysed in the study, mean age was $69.85 \pm$ 10.36 years with youngest being 40 and oldest being 95 years. There were $40(47 \%)$ males and $46(53 \%)$ females in the study population. $(n=86)$

\begin{tabular}{lll}
$\begin{array}{l}\text { Table 1: Status of the heart chamber among the COPD } \\
\text { patients }\end{array}$ & Normal & Dilated \\
Heart Chamber & $49(57 \%)$ & $37(43 \%)$ \\
Right Atrium (RA) & $51(59 \%)$ & $35(41 \%)$ \\
\hline Right Ventricle(RV) & $65(76 \%)$ & $21(24 \%)$ \\
Left Atrium(LA) & $67(78 \%)$ & $19(22 \%)$ \\
Left Ventricle(LV) &
\end{tabular}

Around $40 \%$ of the individuals were having dilated right chambers of the heart and around 20\% with left heart chambers dilatation (Table 1).

\begin{tabular}{|c|c|c|}
\hline PAH category & Frequency & Percent \\
\hline Normal (PASP $\leq 25)$ & 41 & 48 \\
\hline Mild (PASP 25-49) & 19 & 22 \\
\hline Moderate (PASP 50-69) & 19 & 22 \\
\hline Severe (PASP $\geq 70$ ) & 7 & 8 \\
\hline
\end{tabular}

Table 3: Valvular condition among COPD cases $(n=86)$

\section{None Mild Moderate Severe}

\begin{tabular}{llllc} 
Aortic regurgitation (AR) & $71(83 \%)$ & $12(14 \%)$ & $3(3 \%)$ & 0 \\
\hline Mitral regurgitation(MR) & $62(72 \%)$ & $19(22 \%)$ & $2(2 \%)$ & $3(4 \%)$ \\
\hline Tricuspid regurgitation(TR) & $43(50 \%)$ & $18(21 \%)$ & $19(22 \%)$ & $6(7 \%)$ \\
\hline Pulmonary regurgitation(PR) & $86(100 \%)$ & 0 & 0 & 0 \\
\hline Mitral stenosis(MS) & $85(99 \%)$ & $1(1 \%)$ & 0 & 0 \\
\hline Aortic stenosis(AS) & $84(98 \%)$ & $1(1 \%)$ & 0 & $1(1 \%)$ \\
\hline Pericardial effusion (PE) & $85(99 \%)$ & $1(1 \%)$ & 0 & 0
\end{tabular}

Among COPD cases commonest valvular disorder was tricuspid regurgitation (50\%), followed by mitral regurgitation (30\%) other valves were less involved (Table 3 ).

Table 4: Left ventricular functional status among COPD patients: $(n=86)$

\begin{tabular}{|lll|}
\hline Ventricular functional parameter & Yes & No \\
\hline Left ventricular diastolic dysfunction & $32(37 \%)$ & $54(63 \%)$ \\
\hline Concentric left ventricular hypertrophy & $6(7 \%)$ & $80(93 \%)$ \\
\hline Left ventricular systolic dysfunction & $26(30 \%)$ & $60(70 \%)$ \\
\hline
\end{tabular}


There was left ventricular diastolic dysfunction found among $37 \%$ of the individuals with COPD and in $30 \%$ there was left ventricular systolic dysfunction (LVSD) (ejection fraction (EF) $\leq 55 \%$ ) (Table 4.). Among those having LVSD; among COPD patients. ${ }^{4,9} \mathrm{PAH}$ is the measurement of impact of COPD on right heart function and is factor for high mortality among COPD cases. ${ }^{1,3,4,10}$ The right heart chamber dilation was not statistically significant in one previous

Table 5: Various cardiac parameters and its comparison with PAH

\begin{tabular}{|c|c|c|c|c|c|c|c|}
\hline \multirow{2}{*}{ Variables } & \multirow[t]{2}{*}{ Class } & \multicolumn{4}{|c|}{ PAH } & \multirow[t]{2}{*}{ Total } & \multirow[t]{2}{*}{ p-value } \\
\hline & & None & Mild PASP & Moderate & Severe & & \\
\hline \multirow[t]{2}{*}{ RA } & Normal & 40 & 6 & 2 & 1 & 49 & \multirow[t]{2}{*}{$<.001$} \\
\hline & Dilated & 1 & 13 & 17 & 6 & 37 & \\
\hline \multirow[t]{2}{*}{ RV } & Normal & 40 & 6 & 4 & 1 & 51 & \multirow[t]{2}{*}{$<.001$} \\
\hline & Dilated & 1 & 13 & 15 & 6 & 35 & \\
\hline \multirow[t]{2}{*}{ LA } & Normal & 36 & 9 & 14 & 6 & 65 & \multirow[t]{2}{*}{.008} \\
\hline & Dilated & 5 & 10 & 5 & 1 & 21 & \\
\hline \multirow[t]{2}{*}{ LV } & Normal & 33 & 13 & 15 & 6 & 67 & \multirow[t]{2}{*}{.703} \\
\hline & Dilated & 8 & 6 & 4 & 1 & 19 & \\
\hline \multirow[t]{2}{*}{ LVDD } & Yes & 25 & 4 & 3 & 0 & 32 & \multirow[t]{2}{*}{$<.001$} \\
\hline & No & 16 & 15 & 16 & 7 & 54 & \\
\hline \multirow[t]{3}{*}{ AR } & None & 34 & 15 & 16 & 6 & 71 & \multirow[t]{3}{*}{.598} \\
\hline & Mild & 4 & 4 & 3 & 1 & 12 & \\
\hline & Moderate & 3 & 0 & 0 & 0 & 3 & \\
\hline \multirow[t]{4}{*}{ MR } & None & 31 & 12 & 13 & 6 & 62 & \multirow[t]{4}{*}{.151} \\
\hline & Mild & 10 & 5 & 4 & 0 & 19 & \\
\hline & Moderate & 0 & 0 & 1 & 1 & 2 & \\
\hline & Severe & 0 & 2 & 1 & 0 & 3 & \\
\hline \multirow[t]{4}{*}{ TR } & None & 38 & 5 & 0 & 0 & 43 & \multirow[t]{4}{*}{$<.001$} \\
\hline & Mild & 3 & 9 & 6 & 0 & 18 & \\
\hline & Moderate & 0 & 4 & 12 & 3 & 19 & \\
\hline & Severe & 0 & 1 & 1 & 4 & 6 & \\
\hline \multirow[t]{2}{*}{ MS } & None & 40 & 19 & 19 & 7 & 85 & \multirow[t]{2}{*}{.775} \\
\hline & Mild & 1 & 0 & 0 & 0 & 1 & \\
\hline \multirow[t]{3}{*}{ AS } & None & 39 & 19 & 19 & 7 & 84 & \multirow[t]{3}{*}{.896} \\
\hline & Mild & 1 & 0 & 0 & 0 & 1 & \\
\hline & Severe & 1 & 0 & 0 & 0 & 1 & \\
\hline
\end{tabular}

$3(4 \%)$ had mild LVSD (EF=45-54\%), 10(12\%) were having moderate LVSD (EF=30-44\%), and rest $13(15 \%)$ were having severe LVSD $(E F<30 \%)$.

Among the various factors analyzed in echocardiographic assessment; there was significant association between the $\mathrm{PAH}$ with right atrial dilatation, right ventricular dilatation, left atrial dilatation, LVDD, Tricuspid regurgitation $(p<0.05)$ while rest of the parameters did not have.

\section{DISCUSSION}

COPD is a chronic lung parenchymal disease of elderly group usually after 40 years which was found true with our study with mean age of patients being $69.85 \pm 10.36$ years and this is also supported by other studies as well. ${ }^{1}$ Pulmonary arterial hypertension is the common finding with those individuals with COPD and this study revealed 45(52\%) individuals having PAH which is comparable with another study where PAH was $55 \%$ among COPD cases. ${ }^{8}$ In contrast one small study including 50 COPD patients showed PAH in $70 \%$ and while two other shared quite low $38.7 \%, 19 \% \mathrm{PAH}$ study $^{1}$ with severity of the disease while present study showed association of right chamber dilatation and left atrium dilation with $\mathrm{PAH} .{ }^{1}$

In our study, among 86 cases in $37 \%$ of the cases left ventricular diastolic dysfunction and in $30 \%$ of the individual left ventricular systolic dysfunction was present in contrast REPENSAR study revealed slightly lower rate of ventricular dysfunction of $17 \%{ }^{5}$ Same study stresses the congestive heart failure being co-existing comorbidity of COPD cases and it has negative impact on patient survival so timely echocardiogram evaluation is needed to early diagnosis and intervention of the effect of COPD on heart. Echocardiographic evaluation readily and reliably detects the $\mathrm{PAH} .{ }^{5}$ The Copenhagen City Heart Study showed LVH prevalence significantly high in COPD (17.7\%) than without COPD (12.1\%). Same study also stresses, patients having COPD will have high cardiovascular diseases. ${ }^{11}$

Among valvular disorder associated with COPD, tricuspid regurgitation was commonest one (50\%) with different severity in our study and depending on the study sample 
and community it varies and one study showed TR in $77 \%$ of the COPD patients. ${ }^{8}$ Left ventricle abnormalities like dilated left ventricles, LVDD, concentric ventricular hypertrophy, LVSD are also present in significant number of COPD patients in our study accounting 22\%, 37\%, 7\%, 30\% respectively while in another study, left ventricle enlargement was seen in 6\%, LVDD in $12 \%$, LVSD in $13 \% .{ }^{4}$

\section{CONCLUSION}

COPD is in most instances associated with some form of cardiac abnormalities so echocardiographic evaluation in timely basis has pivotal role in early detection of the hemodynamic and mechanical alterations like PAH, LVDD, LVSD, TR, dilated cardiac chambers etc.

\section{RECOMMENDATIONS}

Further is needed. Large multi-centered follow up studies in Nepalese setting. Though it is known that cardiac abnormalities may be associated with COPD patients based on some institutional observation; they have to be properly followed up and timely intervention of the condition is a must.

\section{LIMITATION OF THE STUDY}

The data is based on single center and retrospective study so generalization of the data to the community may not be appropriate and small sample size is the limitation of the study.

\section{CONFLICT OFINTEREST}

There is no conflict of interest and financial disclosure of authors with this study.

\section{REFERENCES}

1. Vikhe V, Shende PS, Patil RS, Tamakuwala KK, Patil AS, Gupta AP. Cardiovascular complications in chronic obstructive pulmonary disease with reference to 2D echocardiography findings. Natl J Med Res. 2013;3(4):385-8.

2. Hilde JM, Skjørten I, Grøtta OJ, Hansteen V, Melsom MN, Hisdal J, Humerfelt $S$, Steine K. Right ventricular dysfunction and remodeling in chronic obstructive pulmonary disease without pulmonary hypertension. J Am Coll Cardiol. 2013 Sep 17;62(12): 1103-11.https://doi.org/10.1016/j.jacc.2013.04.091.

3. Tanaka $\mathrm{Y}$, Hino M, Mizuno K, Gemma A. Evaluation of right ventricular function in patients with COPD. Respiratory care. 2013 May 1;58(5):816-23.PMid:23051582.

4. Freixa X, Portillo K, Paré C, Garcia-Aymerich J, Gomez FP, Benet M, Roca J, Farrero E, Ferrer J, Fernandez-Palomeque C, Antó JM. Echocardiographic abnormalities in patients with COPD at their first hospital admission. Eur Respir J. 2013 Apr 1;41(4):784-91. https://doi.org/10.1183/09031936.00222511.

5. Macchia A, Moncalvo JR, Kleinert M, Comignani PD, Gimeno G, Arakaki D, Laffaye N, Fuselli JJ, Massolin HP, Gambarte J, Romero M. Unrecognised ventricular dysfunction in COPD. Eur Respir J. 2012 Jan 1;39(1):51-8. https://doi.org/10.1183/09031936.00044411.

6. Shrestha B, Dhungel S, Chokhani R. Echocardiography based cardiac evaluation in the patients suffering from chronic obstructive pulmonary disease. Nepal Med Coll J. 2009 Mar;11(1): 14-8.PMid:19769230.
7. Bhattacharyya P, Acharjee D, Ray SN, Sharma RK, Tiwari P, Paul R, De N, Nag S, Bardhan S, Dey R, Ghosh M. Left ventricular diastolic dysfunction in COPD may manifest myocardial ischemia. COPD: Journal of Chronic Obstructive Pulmonary Disease. 2012 May 23;9(3):305-9. https://doi.org/10.3109/15412555.2012.661805.

8. Higham MA, Dawson D, Joshi J, Nihoyannopoulos P, Morrell NW. Utility of echocardiography in assessment of pulmonary hypertension secondary to COPD. EurRespir J. 2001 Mar 1;17(3) :350-5. https://doi.org/10.1183/09031936.01.17303500.

9. Gologanu D, Stanescu C, Ursica T, Balea MI, Ionita D, Bogdan MA. Prevalence and characteristics of pulmonary hypertension associated with COPD-a pilot study in patients referred to a pulmonary rehabilitation program clinic. Maedica. 2013 Sep;8(3): 243-8.

10. Chaouat $A$, Naeije $R$, Weitzenblum E. Pulmonary hypertension in COPD. Eur Respir J. 2008 Nov 1;32(5):1371-85. DOI: https:// doi.org/10.1183/09031936.00015608.

11. Lange P, Mogelvang R, Marott JL, Vestbo J, Jensen JS. Cardiovascular morbidity in COPD: A study of the general population. COPD: J Chronic Obstr Pulm Dis. 2011 Feb 1;7(1):5-10. DOI:https:// doi.org/10.3109/15412550903499506. 